I understand that Dr. Walker dates the use, or at least the first publication of the use, of gutta-percha moulds from about ten years ago; but cursets of both gutta-percha and leather were modeled on the trunk at a very much earlier period; indeed, I constructed two such splints for patients in the Charing cross Hospital in '62 and '63. $\mathrm{Mr}$. Spratt, the instrument and splint maker of Brook-street, adapted a leather mould for one of my patients twelve years ago; but he informs me that he bas been in the babit of making them for more than twenty years, and unless in the case of refractory infants, always in the recumbent position. Of course he constructs them either of leather or guttapercha as the surgeon may direct, but prefers the former material. I am not aware that in moulding these splints the many-tailed bandage has ever been employed, and believe that this ingenious adaptation of the appliance Dr. Walker may claim as bis own.

I have long discontinued the use of such splints, as not proving satisfactorv, partly because they do not, after a little time, afford efficient support, as is proved by the fact that it is now the fasbion to add crutch handles; partly because if there be any considerable deformity, it is impossible to avoid a fold at a level with the angle; but chit fly because the horizontal position does not put the spine into a sufficiently good posture to begin with.

It is impossible to describe in a short paper, such as I wrote for your journal on the 26 th May, still less in a letter like the present one, all the theoretical and practical advantages of applying a plaster-of-Paris bandage during suspension of the body, nor, indeed, all the precantions to be adopted. They will be found fully discussed in the third edition of my work on Spinal Curvatures; from which, I think, it will he evident why I must altogether repudiate the suggestion of $\mathrm{Dr}$. Walker, that the plaster-of Paris, if preferred to gutta percha, should be applied while the patient lies on a soft bed. Suspension is one of the great advantages of this method; not, as Dr. Walker seems to think, a mere arrangement for convenience in applying the bandage. Indeed, it constitutes a point in the treatment of angular curvature which, having fully tested, I would not willingly relinquish.-I remain, your obedient servant,

George-street, Hanover-square, 20th July, 1877 .

$$
\text { Richard Barweli. }
$$

\section{HOSPITAL TREATMENT OF MEASLES.}

\section{To the Editor of THE LANCET.}

SrR,-The paragraph in last week's LANCET on the mor. tality attending the treatment of measles in hospital requires a word of explanation. It is no new experiment to treat measles in the London Fever Hospital. A death-rate of 10.5 per cent. for this disease among the patients in this institution would appear unusually high had it not been stated that this rate had been calculated on so small a number of cases as nineteen, of which two died. It should be known that a large number of patients in the London Fever Hospital are received from other hospitals, where the majority of them are under treatment for some or her disease at the time of being attacked with fever. The two cases of measles which died were received in this way ; both patients had mild attacks of measles, but one was at the time suffering from extensive suppuration of the glands of the neck, and the other from acute tuberculosis. Notwithstanding such cases as these, it is not found that the death-rate from measles is high when calculated on a large number. Thus during the years 187176 inclusive, 122 patients were admitted, and of these only three died. There is, therefore, every reason to believe that no increase of mortality attends the treatment of measles in hospital; and, seeing that more that 1700 persons died of this disease in London last year, it cannot be doubted that the early isolation of such cases is urgently required. - I am, Sir, jour obedient servant,

London Fever Hospital, July 24th, 1877. SHIRLEY MURPHY.

\section{To the Editor of The LaNCET.}

SIR,-I observe that, in a paragraph of this week's LANCEr on the hospital treatment of measles, it is supposed that the London Fever Hospital has inaugurated this prictine, It is not so, however. Here, as no doubt in London also, stray cases of measles occurring in adults-e.g., servantshave always been admitted to our general hospital, but I refer to the reception of children, which, I take it, you have especially in mind. Since 1872, when the hospital accommodation of the local authority of Glasgow was largely extended, we have endeavoured to introduce the isolation and treatment in hospital of children, affected with measles. But up to 1st May, 1877, we only succeeded in removing 159 cases. Of these five died, or a little over three per cent. Yet in that period over 1300 children died of measles in this city. I attribute our ill success (1) to the extreme youth of the patients. It is impossible to force removal of infants, even when it is obvious that they would be transferred from circumstances of misery to those of enmfort. (2) But at the root, both of the opposition of parents and the reluctance on my part to violate the parental sentiment, is this, that parent look upon "the measles" as, like teething, a process of nature, In fact, the measles is the more natural of the two, if we are to judge from the readiness to interfere in the one and the backwardness in the other. Still worse is the general disposition in the profession to ridicule the idea of treating such a disease in hospitals. The proportion of measles cases which pass under professional and parental observation relative to deaths caused therehy seems to be so immense, that practically the body of the child dead of measles is like that of the proverhial dead donkey-something that nobody ever sees. Yet, this disease alone may add two to our death-rate per 1000, a contribution which all the "fevers" together have nut made for six years.

Still, the effect of perseverance and education is very great in sanitary matters. The bospiral treatment of scarlet fever was regarded with equal disfavour when first commenced; but now, in one year, we have treated 720 cases, and we do not hesitate about compelling removal in fitting circumstances. One humane and politic concession made to parents by the local autbority here I recommend to the notice of others. We admit mothers along with children under five years if they desire it, and when a family is laid down at once, as often happens, we keep them together under the mother's eye in the wards. In many cases this is a sore trial to the temper of nurses, a strain on hospital discipline, and even an ivjury to the children, so ignorant and injudicious are the poor women; but it disarms opposition, and extends the reputation of hospitals. A woman who, in these circumstances, leaves the institution pleased, becomes a friend in the locality where she lives.

My experience leads me to believe that if local authorities do their duty by providing hospitals whose structure and management beget confidence, by maintaining a staff of judicious, intelligent men to go about and look for infectious disease, and thereby keeping up a constant pressure towards the hospital, in a very short time the community will move in the right direction. But it is not from the parochial organisation this will be got. The nature of the action required is entirely foreign to the constitution and habits of the parochial mind; and, indeed, the work to be done is neither of the nature of charity nor of legal relief. It is interference with the individual for the general goodthe maintenance from a fund to which all contribute of any single contributor whose sickness is dingerous to all. This is the broad principle which we endeavour to work out in Glasgow, and with an increasing mrasure of success.

I am, Sir, your obedient servant, Jas. B. Russell, Med. Officer of Health.

Sanitary Department, Montrose-street, Glasgow, July 24th, 1877.

\section{THE ARMY MEDICAL DEPARTMENT.}

\section{To the Editor of THE LANCET.}

Sir, - Years have now passed since the commencement of those unhappy dissensions which have made the Army Medical Department a discredit to our military system, and a bugbear to successive War Ministers.

Great changes were proposed, determined on, and $\epsilon$ ffected, such as the arbitrary and sudden removal of medical officers from their regiments, with an absence of tant and a want of consideration st which all stoud amazed. 